Journal of University of Babylon for Engineering Sciences, Vol. (27), No. (1): 2019.

\title{
Stabilization of Soils Using Chemical Admixtures: A Review
}

\section{Mohammed N J Alzaidy}

Civil Engineering Department, Mosul University, Nineveh Province, Iraq

mohammednawaf@uomosul.edu.iq

\begin{tabular}{|l|l|l|}
\hline Submission date:- 17/12/2018 & Acceptance date:- 8/1/2019 & Publication date:- 13/1/2019 \\
\hline
\end{tabular}

\begin{abstract}
Searching for the best soil stabilizer to overcome problems occur by the soft soils are still being the main concern, not only to achieve the required soil engineering properties but also by considering the cost and the effect to the environment. This review paper presents the results of experimental researches on soil stabilization by using the most chemical admixtures, which involved cement, lime and fly ash, and their effectiveness in the engineering properties of soil. Based on the literature review, the results show that addition of these chemical additives lead to significant improvement in workability, strength, durability and mechanical behaviour. On the other hand, it lead to a reduction in shrinkage, plasticity, compressibility and swell characteristics of soil. Also, the curing duration had significantly improved the strength properties of the stabilized soil with chemical additives. Using of each chemical additive and its suitability for a specific soil is highlighted in the research.
\end{abstract}

Keywords: Cement, Lime, Fly ash, Chemical admixtures, Soil stabilization 
Journal of University of Babylon for Engineering Sciences, Vol. (27), No. (1): 2019.

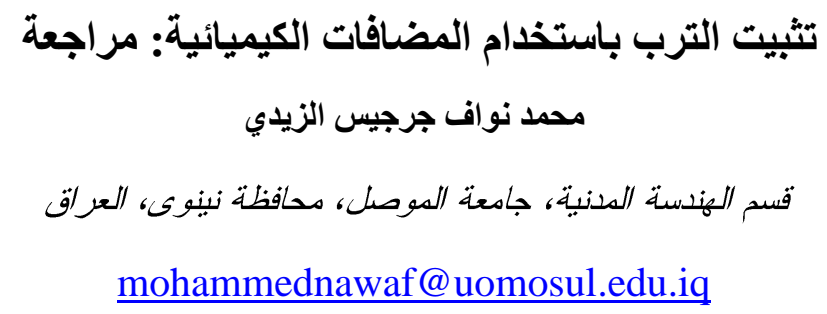

ألخلاصة

إن عملية البحث عن أف ضل مادة لنتييت التزبة لغرض التغلب على مـ شاكل التزب الـ ضعيفة ما زالت جارية، ليس فقط

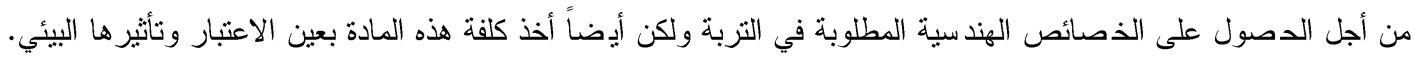
يعرض هذا البحث مراجعة للار اسات العملية الـابقة الخاصة بنتيبت النربة باستخدام الدضافات الكيميائية الشائعة الاستخدام و التي تشمل الـمنت والنورة والرّماد المنطاير وتأثثر ها في الذصائص الهند سية للترب. بينت نتائج نلك الدراسات بأن إضافة

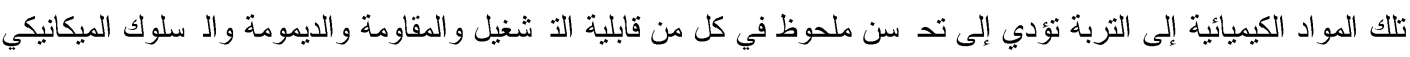

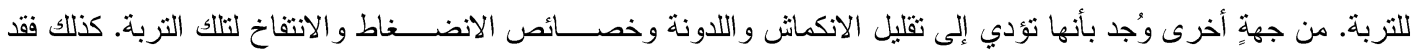

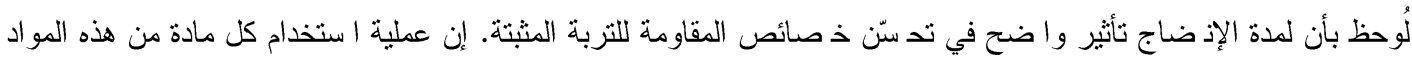

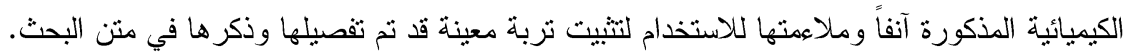
الكلمات الادالة: السمنت، النورة، الرّماد المنطاير، المضافات الكيميائية، تثيبيت التربة

Introduction المقدمة

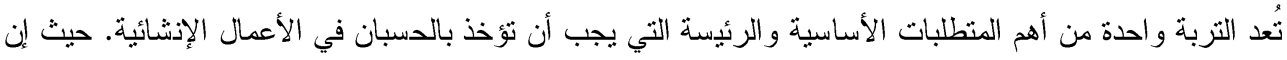

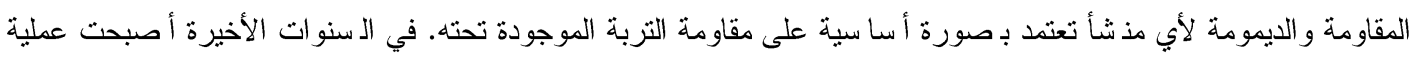
إذ شاء طبقة الأ ساس للطرق تتم با ستبدال طبقة التربة الـ ضعيفة بمادة الد صى الخابط أو ما تُعرف بالتيكلة الجبلية. إن كلفة

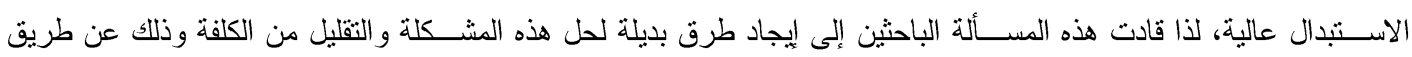

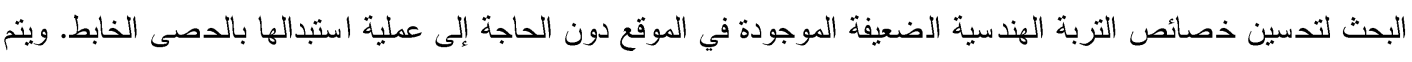

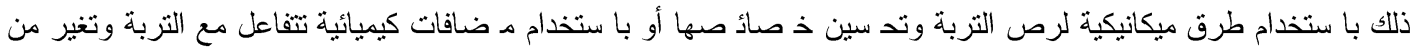

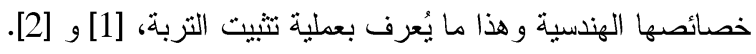

إن عملية تثيت التربة تُعرف على نطاق واسع بأنها طريقة بديلة وفعّالة لتدسين خصائص التربة الهند سية عن طريق

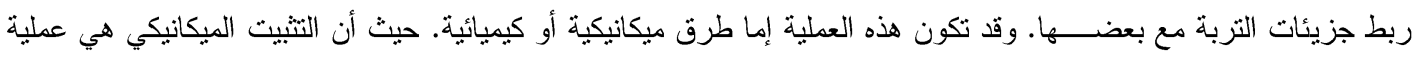

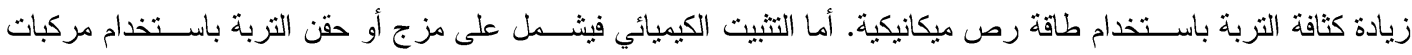

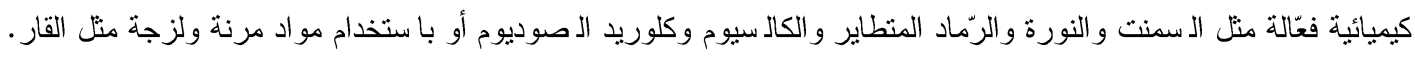

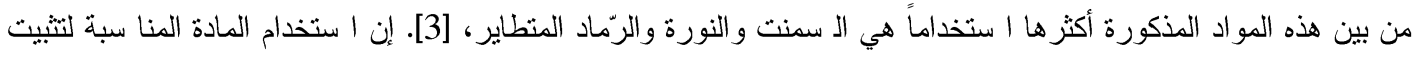

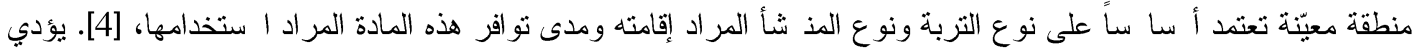

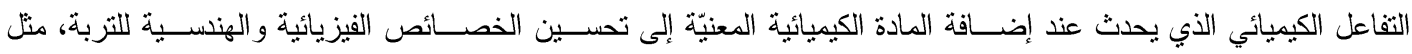

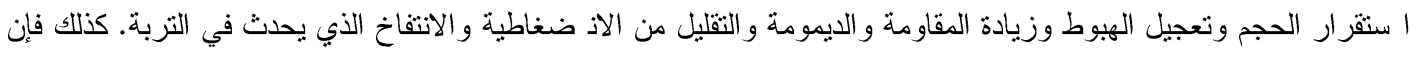

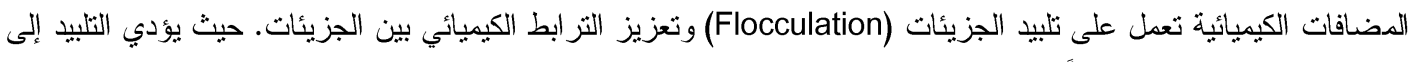

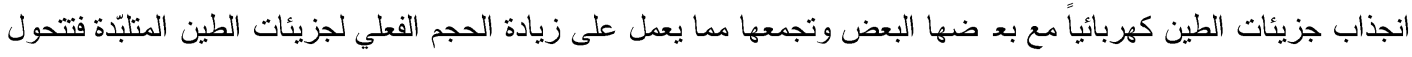

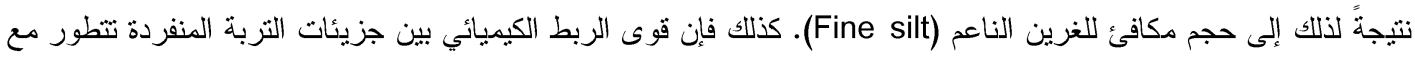

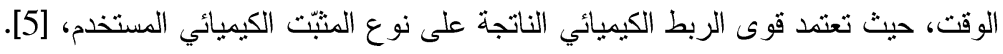


إن الهدف من هذا البحث هو مر اجعة ما تو صتّت إليه الدر اسات العملية ال سابقة والخاصة بتثيبت التزب بالد ضافات الكيميائية

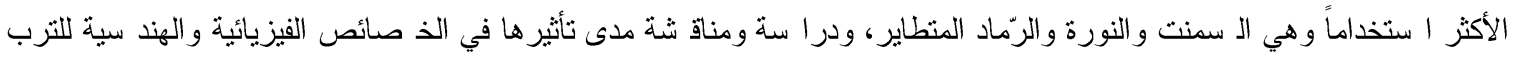

\section{2. المضافات الكيميائية المستخدمة في تثبيت التربة Chemical admixtures used in soil stabilization}

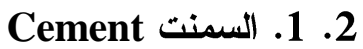

يُعد السمنت من أقدم المواد المستخدمة في تنييت التربة منذ اختراع تقنية تثيت الترب في عام 1960 ولاسيما في إنثاء الطرق،

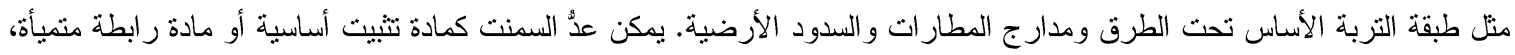

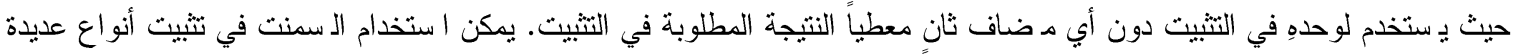

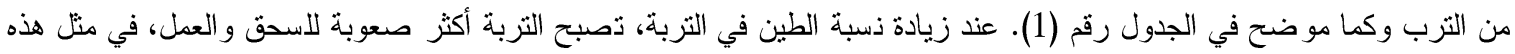

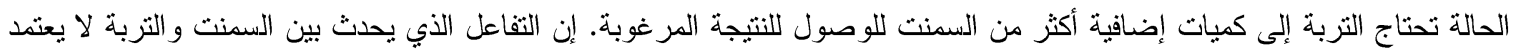

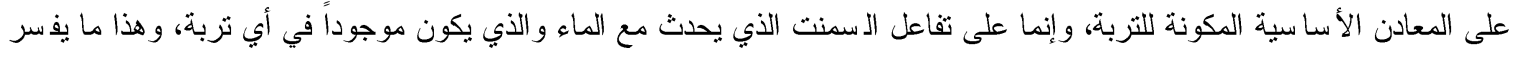

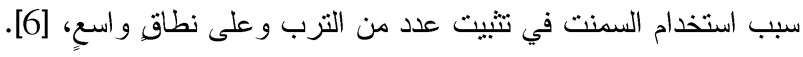

في هذه التنتية، يتم مزج السمنت مع الماء و التزبة باستخدام أجهزة خاصة في الموقع. يؤدي مزج السمنت مع التربة إلى حدوث

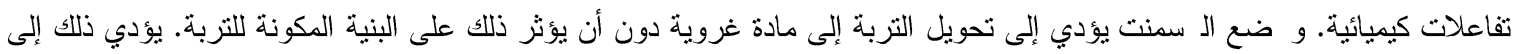
تصلب التربة المثبتة بالسمنت، وتعتمد عملية التصلب هذه على على عدد من العوامل من أهمها:

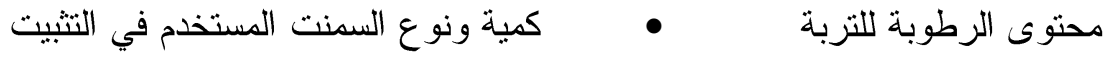

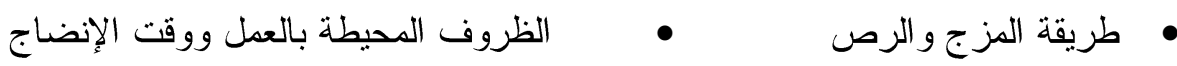

$$
\begin{aligned}
& \text { • طبيعة ومكونات التزبة }
\end{aligned}
$$

إن أكثر الثرب ملاءمةً للتثيت بال سمنت هي التربة المتكونة من مزيج مندرج من الرمل والد صى أو ما تُعرف بالتنيكلة النهرية

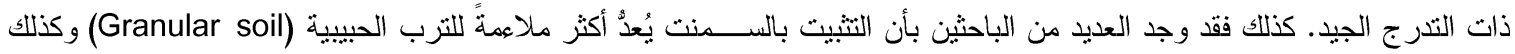

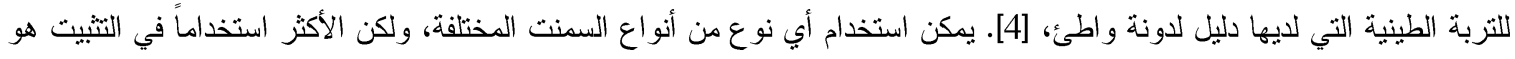

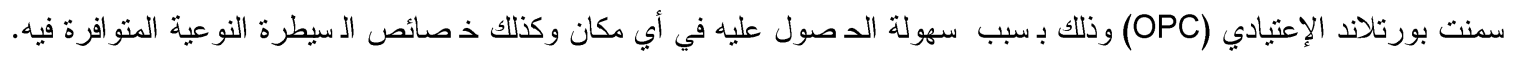
يو ضح الجدول رقم (2) التركيب الكيميائي لسمنت بورنتاند الاعتيادي. أما فيما يخص كمية السمنت المستخدمة في التثييت فهي بصورة

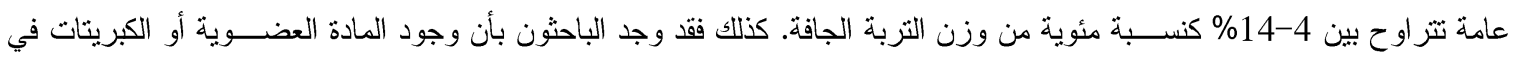

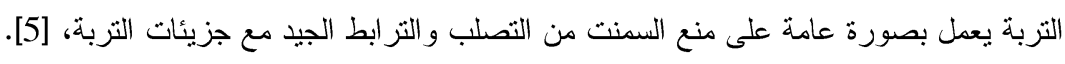




\section{الجدول (1): المضافات الكيميائية المستخدمة في التثبيت وملاعمتها مع الترب، [7]}

\begin{tabular}{|c|c|}
\hline التزبة الأكثر ملاعمة & المادة المستخدمة في التثيبت \\
\hline 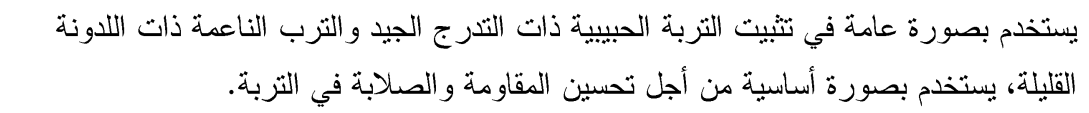 & السمنت \\
\hline يستخدم في تثبيت التزب ذات اللدونة العالية من أجل تقليل اللدونة ويعمل على زيادة قابلية التشغيل & النورة \\
\hline 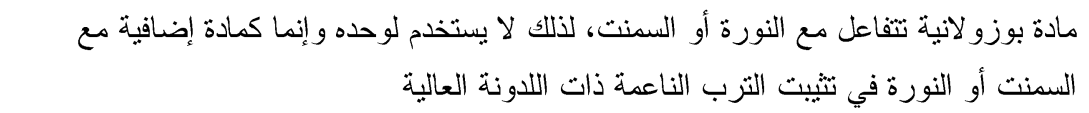 & الرّماد المنطاير \\
\hline تشتخدم بنجاح في تثييت أنواع مختلفة من الترب منل الترب الحبيبة والناعمة. & السمنت-النورة-الرّماد المتطاير \\
\hline
\end{tabular}

الجدول (2): التركيب الكيميائي لسمنت بورتلاد الاعتيادي، [6]

\begin{tabular}{c|c}
\hline النسبة المئوية (\%) & Alumina $\left(\mathrm{Al}_{2} \mathrm{O}_{3}\right)$ \\
\hline $9-5$ & Silica $\left(\mathrm{SiO}_{2}\right)$ \\
\hline $25-19$ & Calcium oxide $(\mathrm{CaO})$ \\
\hline $64-60$ & Ferric Oxide $\left(\mathrm{Fe}_{2} \mathrm{O}_{3}\right)$ \\
\hline $4-2$ & Tri-calcium silicate $\left(\mathrm{C}_{3} \mathrm{~S}\right)$, Di-calcium silicate $\left(\mathrm{C}_{2} \mathrm{~S}\right)$, Tetra-calcium aluminates \\
\hline $9-5$ &
\end{tabular}

إن اكت ساب المقاومة للتربة عند نتثيتها بال سمنت يحدث نتيجةً لعدد من التفاعلات و التي ذن شمل التميؤ والتبادل الأيوني و الكربنة و التفاعلات البوزو لانية، [8] وأدناه توضيح هذه التفاب تلتهاعلات:

التميؤ: تبدأ عملية التميؤ عند إضافة الماء إلى الـ سمنت. إن عملية تميؤ الـ سمنت هي سريعة ذ سبياً وتؤدي إلى اكت ساب المقاومة للتربة

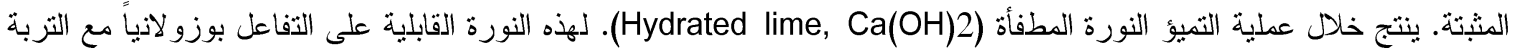

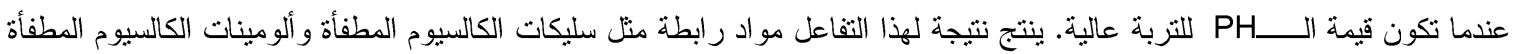
و التي توفر التزابط الوثيق الذي يحدث بين جزيئات التربة.

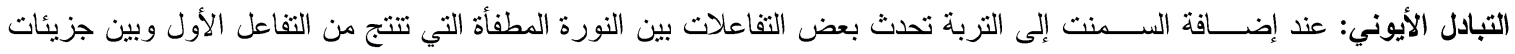

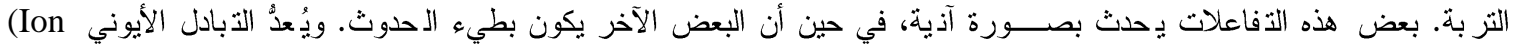

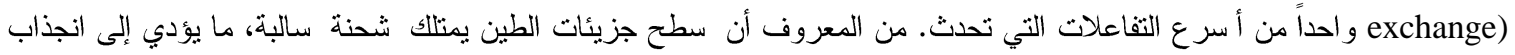

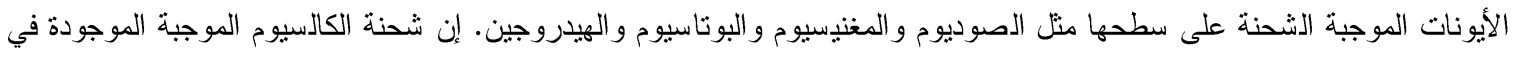

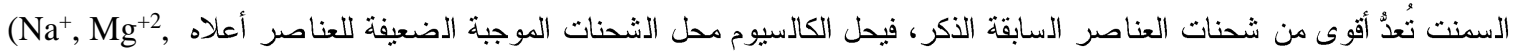

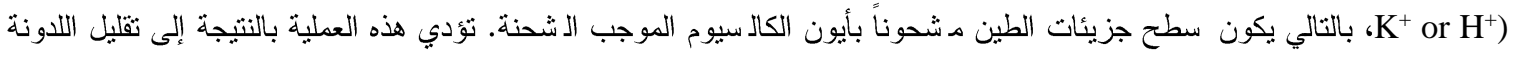


التفاعل البوزولاتي: بعد اكتمال الثفاعل الـ سابقة فإن أي كمية إضافية من الـ سمنت سوف نتفاعل كيميائياً مع معادن الطين الموجودة في

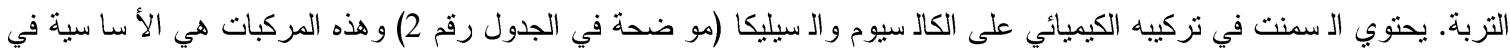

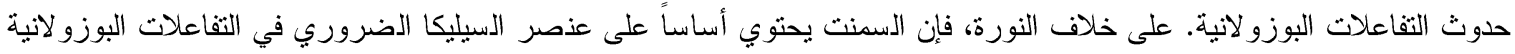

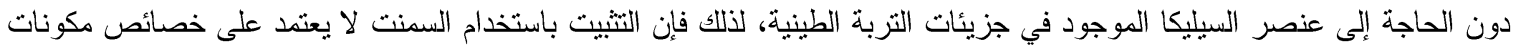

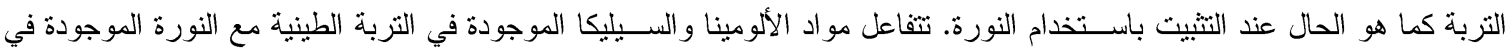

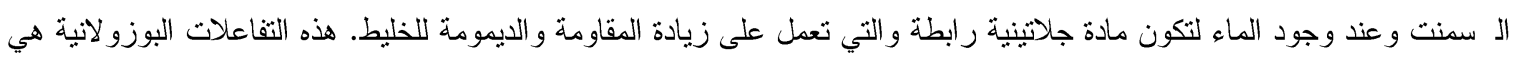

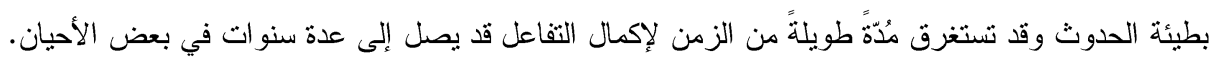

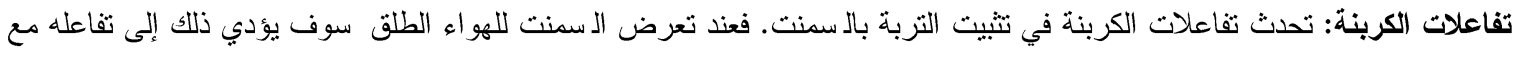

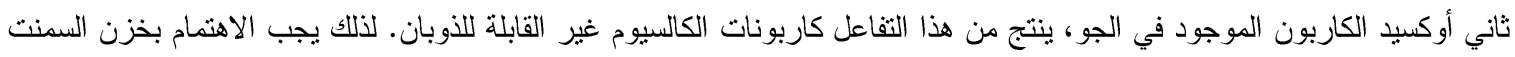

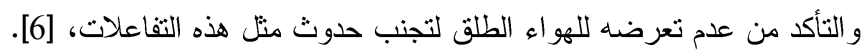

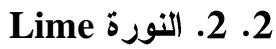

النورة هي الد ضاف الكيميائي الثناني الـ شائع استخداماً في نثتيث الترب الطينية. إن عملية اختيار الكمية الملاعمة من النورة في

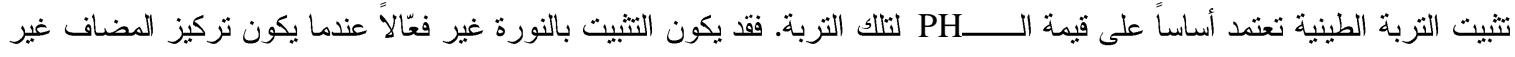

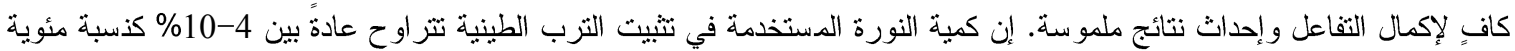

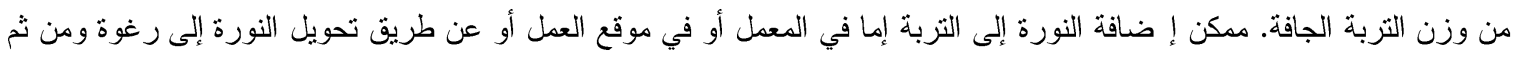

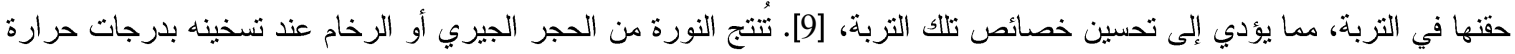

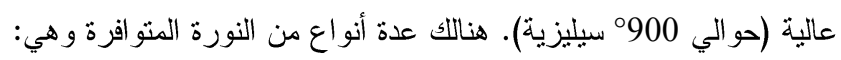

$$
\text { • • }
$$

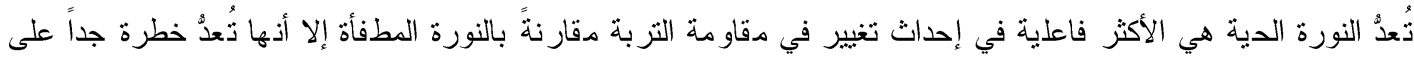
ال صحة. عند إضافة النورة إلى التربة فإن سل سلة من التفاعلات الكيميائية سوف تحدث و التي ذّ شمل التبادل الأيوني والتجمع والتلييد

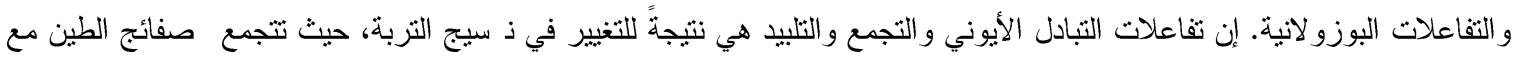

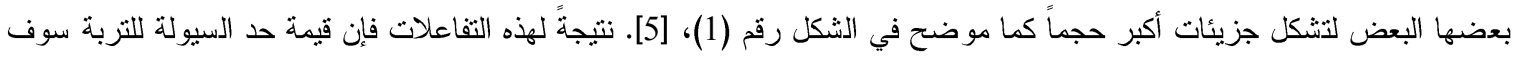

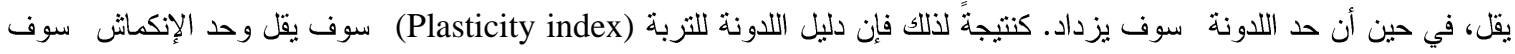

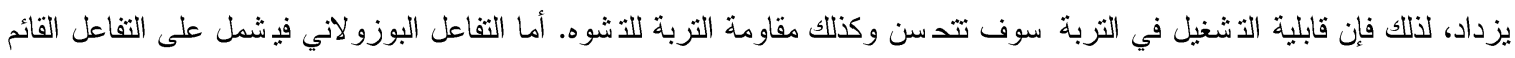

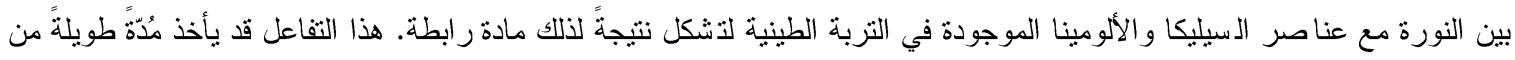
الزمن، وينتج من هذا التفاعل حرارة عالية ويؤدي إلى زيادة المقاومة للتربة المثبتة بالنورة.

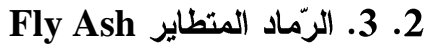

في السنوات الأخيرة الماضية، تحرّى العديد من الباحثين عن إمكانية استخدام المصادر الطبيعية والمعادن الصناعية في عمليات

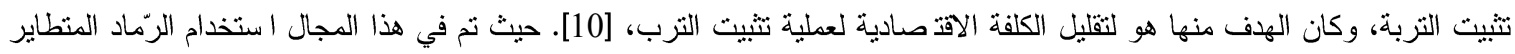

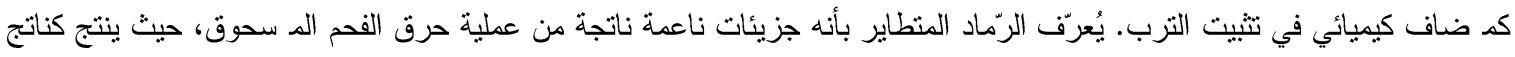

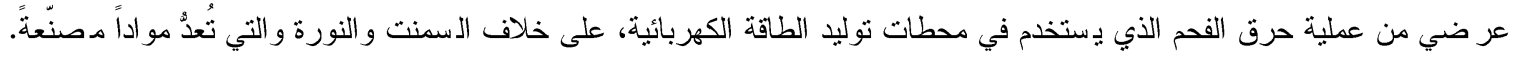

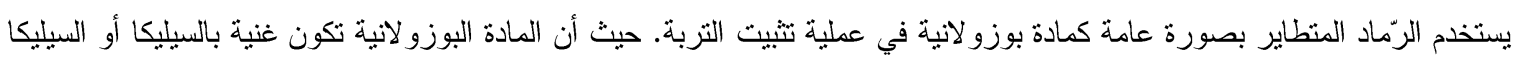

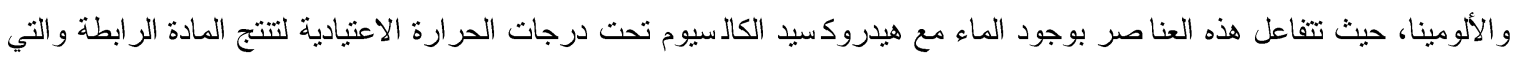

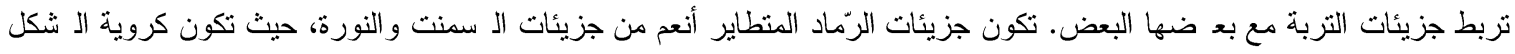




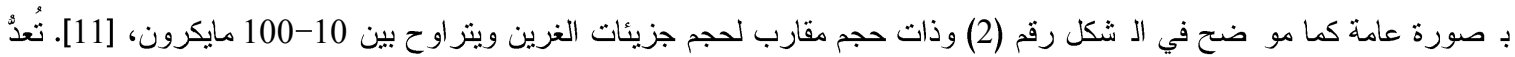

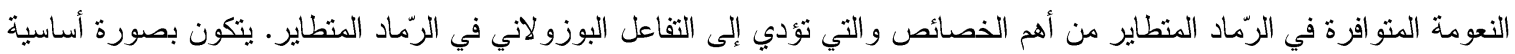

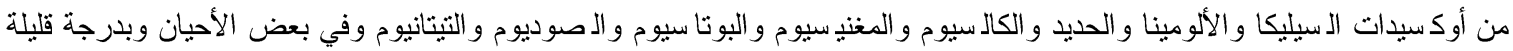

الكبريتات، [11].

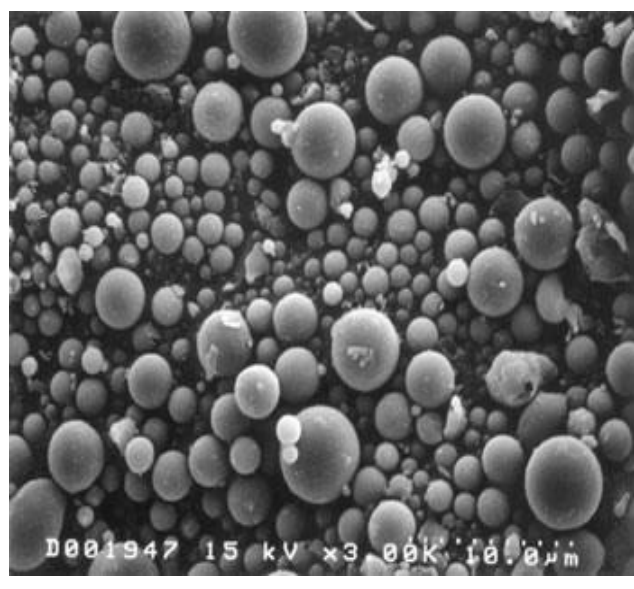

الشكل (2): جزيئات الرّماد تحت المجهر 2000 مرة [11] تكبير

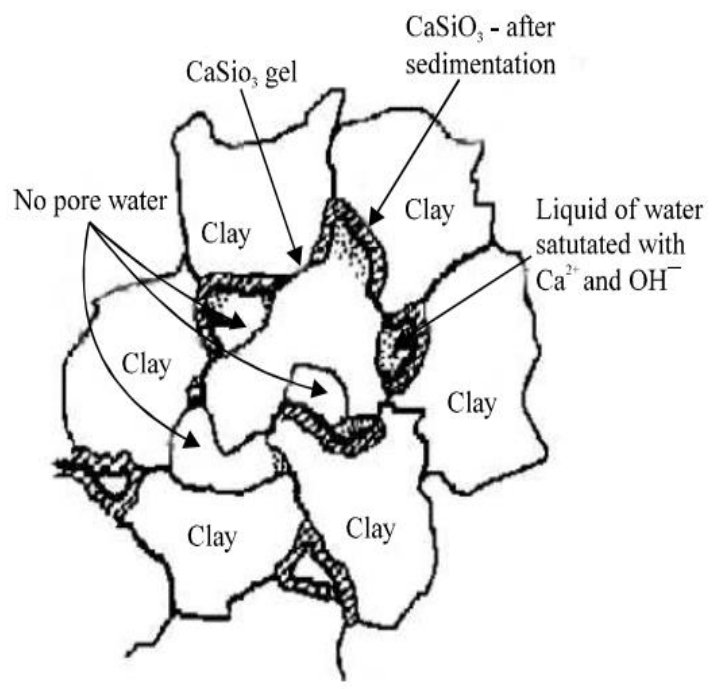

الثكل (1): أساسيات التفاعل بين النورة والتربة الطينية،

[5]

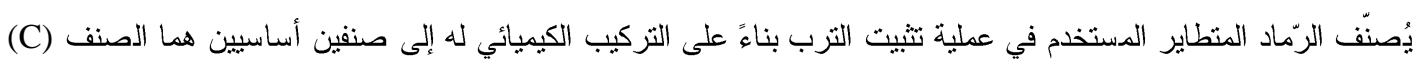

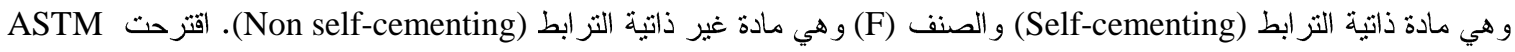

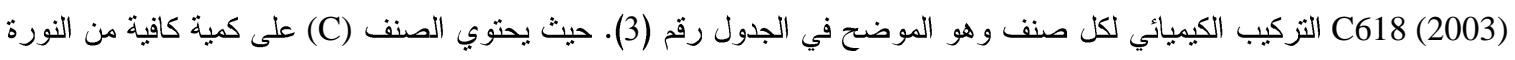
لا تقل عن 20 CaO

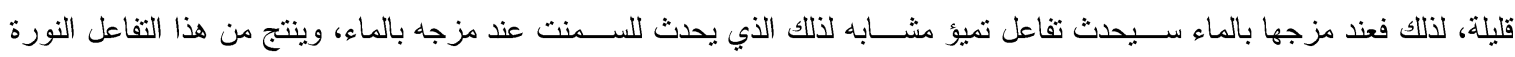

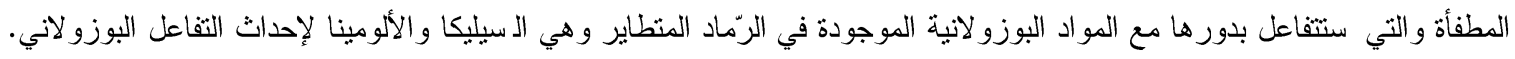

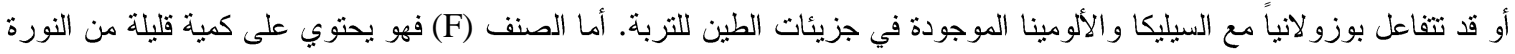

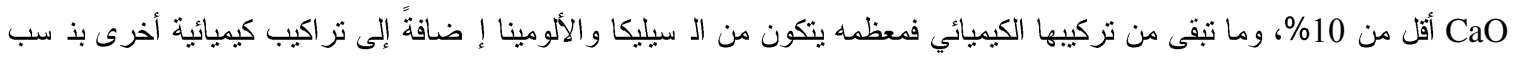

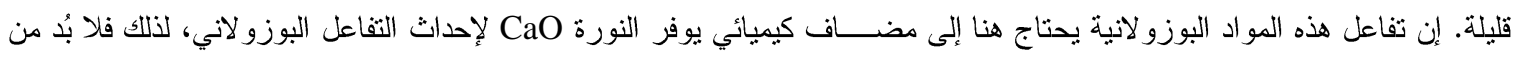

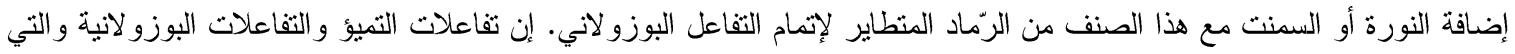

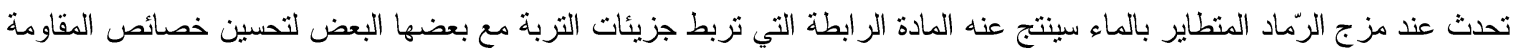

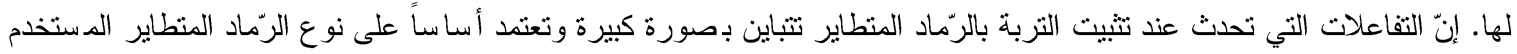

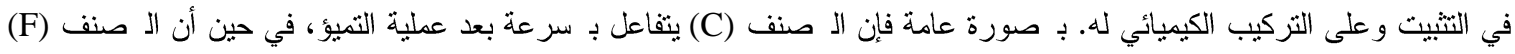

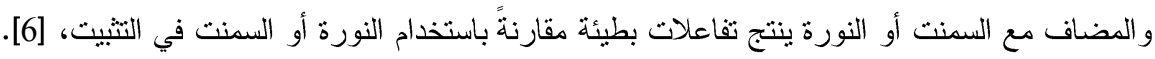

يعرض الجدول رقم (3) التركيب الكيميائي للرماد المثطاير بصــنفيه، [12]. من الجدول بمكن ملاحظة بأن المحتوى

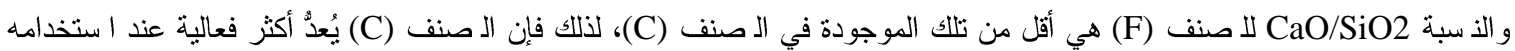

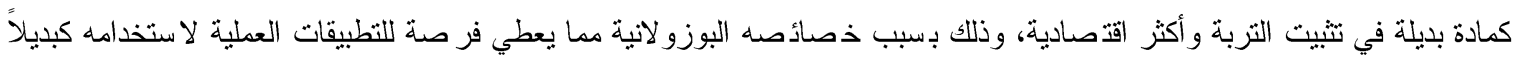


عن الســـت أو النورة، [13]. إنّ كمية الرّماد المتطاير المســخدمة في البحوث العملية تتز اوح بين 5-20\% كنســبة من وزن التربة الجافة.

الجدول (3): التركيب الكيميائي للرماد المتطاير القياسي، [12]

\begin{tabular}{|c|c|c|}
\hline \multicolumn{2}{|c|}{ النسبة المئوية (\%) } & \multirow{2}{*}{ المركب الكيميائي } \\
\hline F F F F F F F & الصنف C & \\
\hline 55 & 40 & Silica $\left(\mathrm{SiO}_{2}\right)$ \\
\hline 26 & 16 & Alumina $\left(\mathrm{Al}_{2} \mathrm{O}_{3}\right)$ \\
\hline 7 & 6 & Ferric Oxide $\left(\mathrm{Fe}_{2} \mathrm{O}_{3}\right)$ \\
\hline 9 & 24 & Calcium oxide $(\mathrm{CaO})$ \\
\hline 2 & 2 & Magnesium oxide $(\mathrm{MgO})$ \\
\hline 1 & 3 & Sulfate oxide $\left(\mathrm{SO}_{3}\right)$ \\
\hline 6 & 6 & Loss of ignition (LOI) \\
\hline
\end{tabular}

3esults based on the literature review النتائج التي توصتّت إليها الاراسات السابقة

Cement 3. 1 السمنت

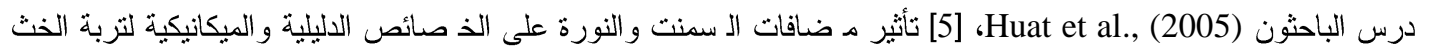

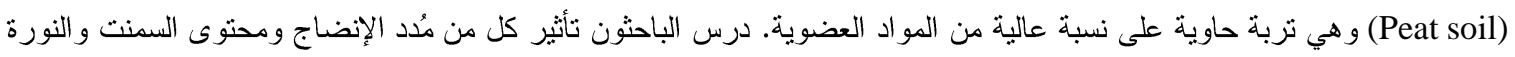

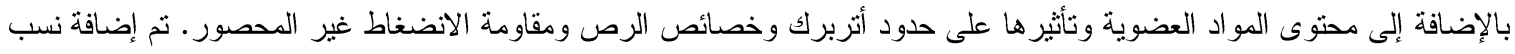

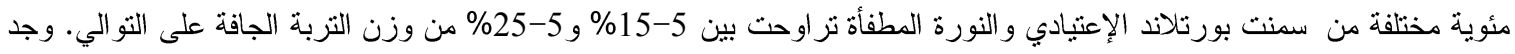

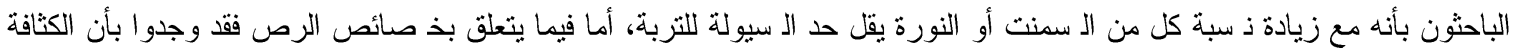

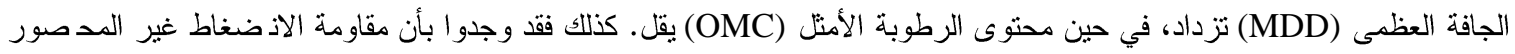

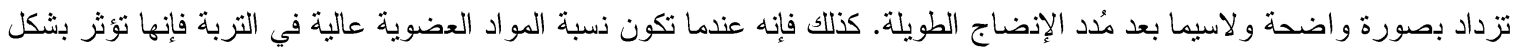

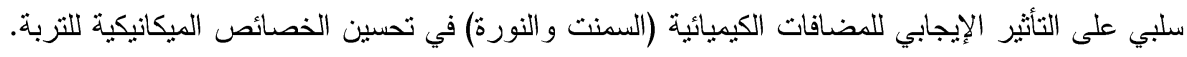

ودرس الباحثنان (2013) Sas and Gluchowski، [14] نأثير التثيت بال سمنت على الذ صائص الميكانيكية لنربة منما سكة

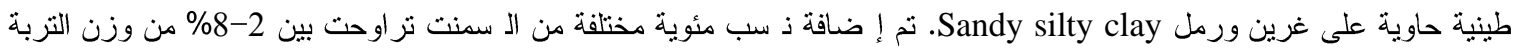

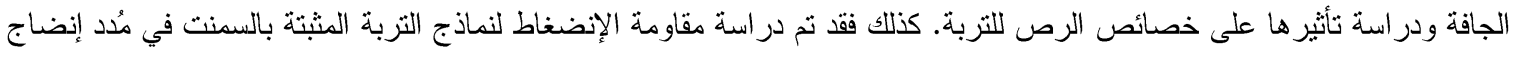

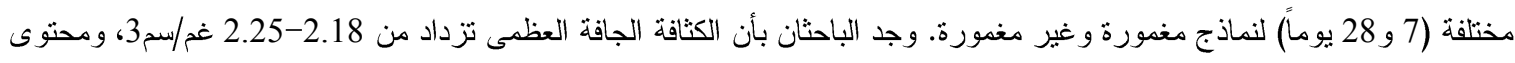

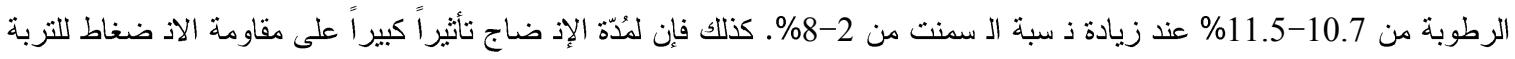

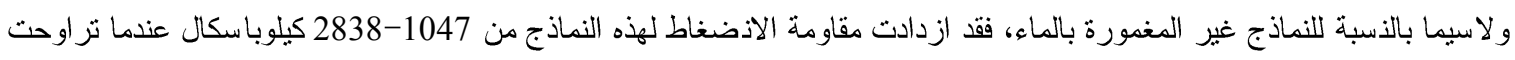

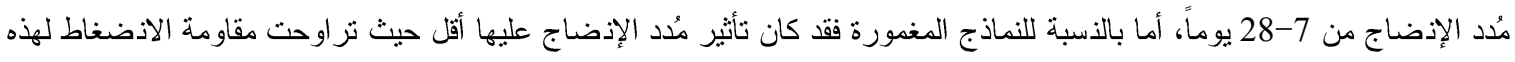

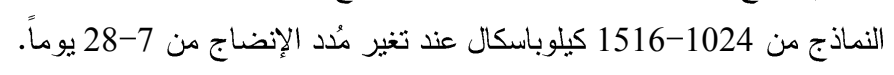

ودرس الباحثان (2017) Pandey and Rabbani) [4] تأثثر التثييت بال سمنت لتربة رملية حاوية على غرين وطين Clayey

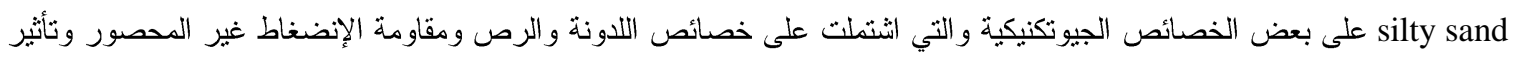

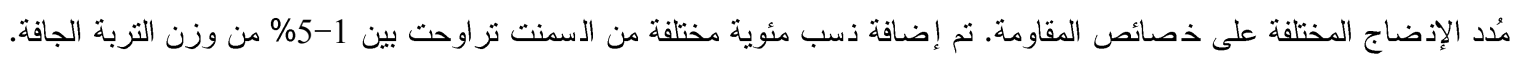

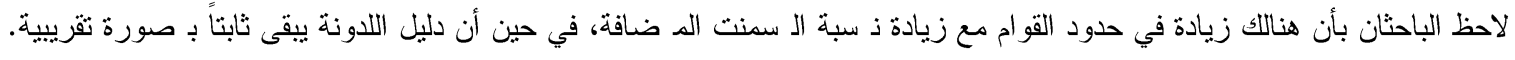

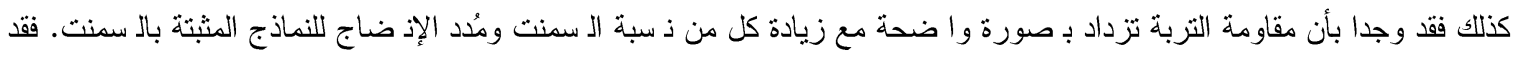


Journal of University of Babylon for Engineering Sciences, Vol. (27), No. (1): 2019.

ازدادت قيمة مقاومة الإن ضغاط غير المد صور من 80-700 كبلوبا سكال عندما تغيرت ذـ سبة الـ سمنت من 1-5\% لمُدّة إذ ضاج يوماً واحداً، في حين أصبحت القيمة 1070 كيلو باسكال عندما تم فحص النماذج بعد 14 يوماً من الإنضاج.

Lime 3 النورة

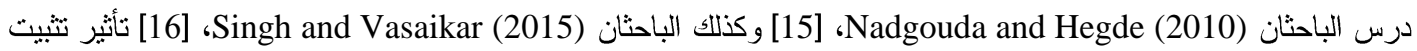
الترب الاتتفاخية با ستخدام ذسب مختلفة من مضافات النورة على الذصائص الهند سية لها والمنمثلة بدليل القو ام و الرص وفحص ذسبة

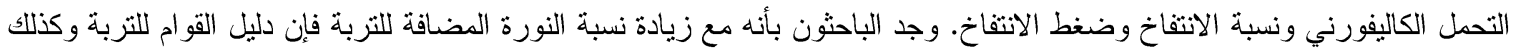

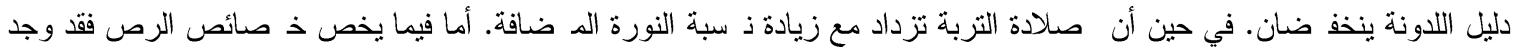

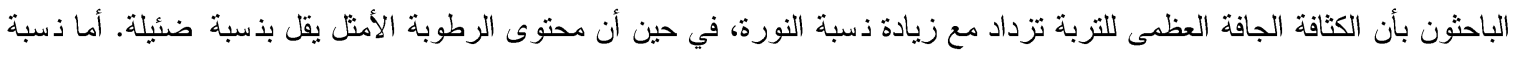

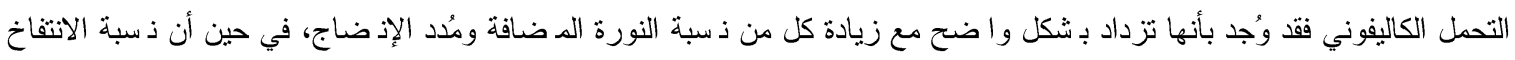

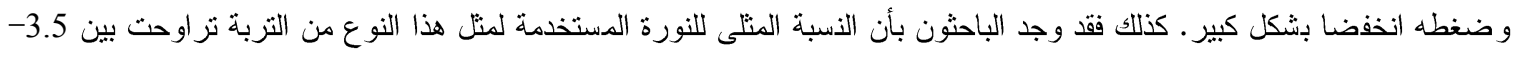

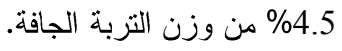

ودرس الباحثان (2012) Sharma and Sahoo، [17] تأثير إضافة كل من النورة والرّماد المنطاير على خد صائص المقاومة

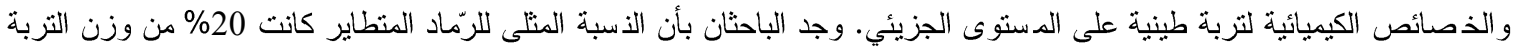

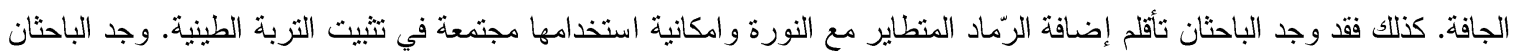

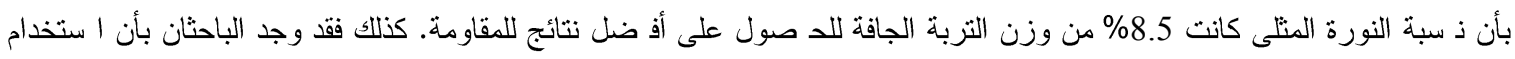
الرّماد المنطاير لوحده في تنييت التربة الطينية يعمل على تحسين الخصائص الجيوتكنيكية لها ولكن بكفاءة أقل من استخدام النورة. ودرس الباحثون (2013) و..Ahmed et al، [18] تد سين خصائص المقاومة لتربة طينية باستخدام مضافات السمنت و النورة

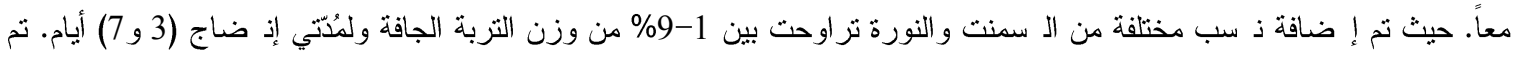

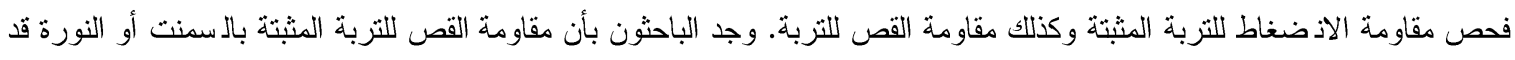

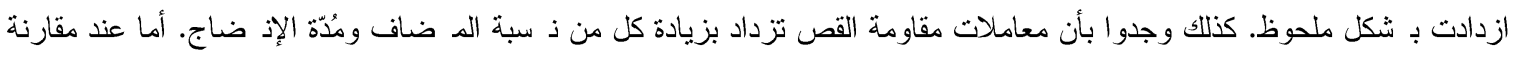

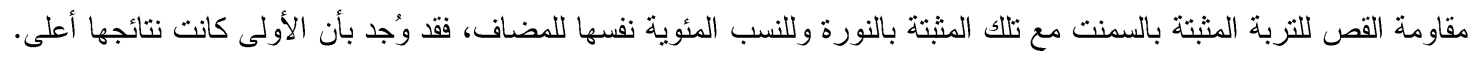
ودرس الباحثان (2014) Ochepo and Joseph، [19] تأثثر إضـــافة النورة على خصـــائص المقاومة لنزبة طينية وكذلك

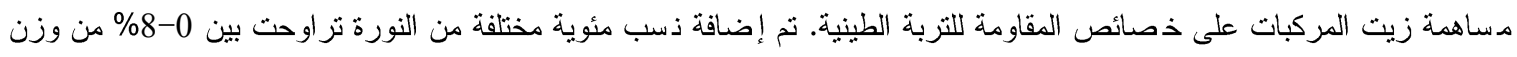

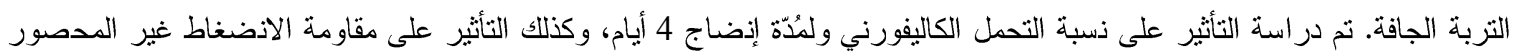

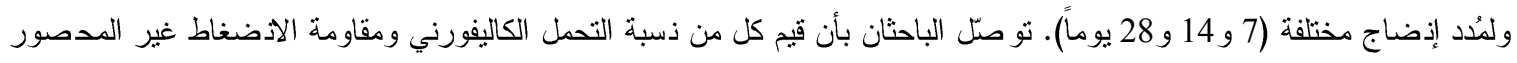

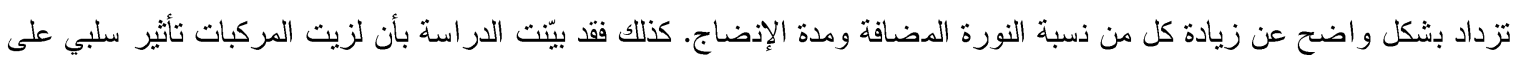

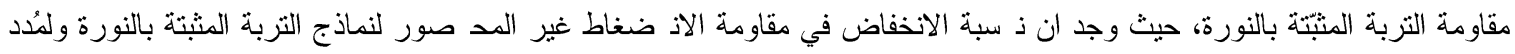

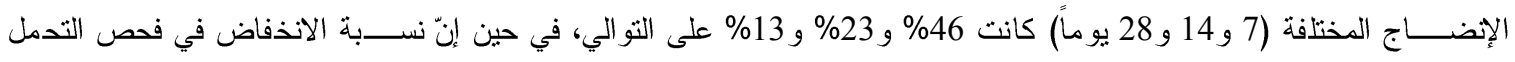

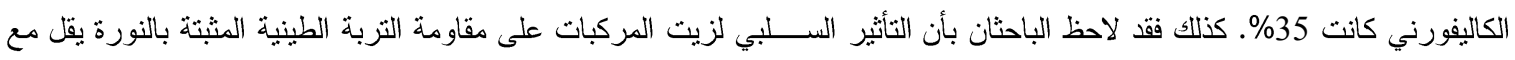

$$
\text { زيادة كل من نسبة النورة المضافة ومُدّة الإنضاج. }
$$

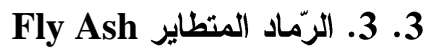

معظم الرمّاد المنطاير الذي يتم إضـــافته في تتيبت التربة يُعدّ مادة رابطة ثانوية، إذ لا تكفي هذه المادة منفردةً أن تُعطي النتائج

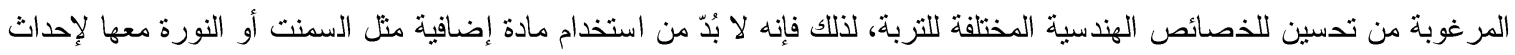

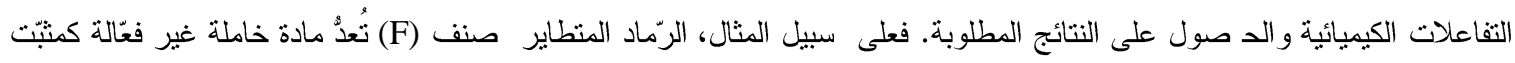

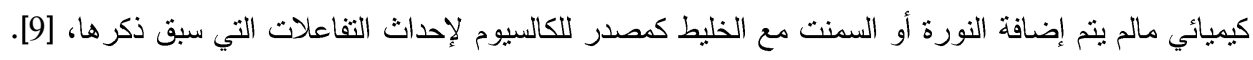


درس الباحثون (2003)، Shah et al., [203 تأثير تنثيث تربة طينية حاوية على غرين واطئة اللدونة بنسب مختلفة من النورة--

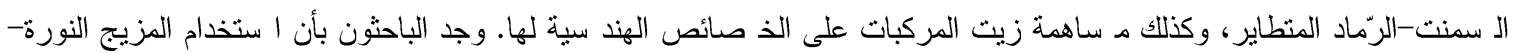

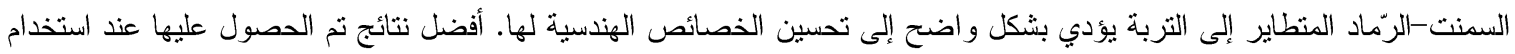
ذ سب 10\%-5\%-5\% للنورة- الـ سمنت- الزمّاد المنطاير من وزن التربة الجافة على التو الي. كذلك فقد لاحظ الباحثون بأن هـ ساهمة

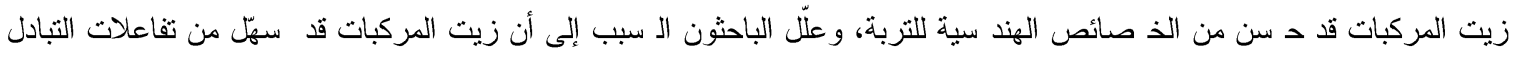
الأيوني و التجمع والتلبيد لجزيئات التربة مع بعضها البعض إضافةً إلى التفاعلات البوزو لانية.

ودرس الباحثتون (2012) ,Jongpradist et al., [21] تأثثر إضافة ذسب مختلفة من الرّماد المنطاير على الاسنت واستخدام

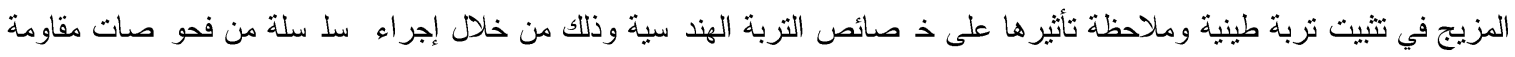

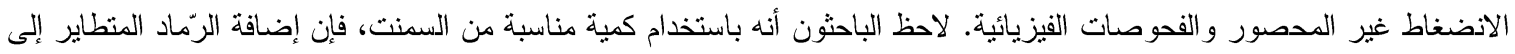

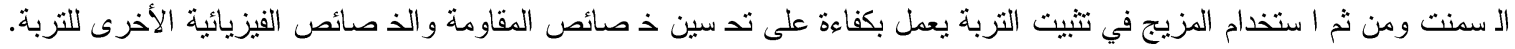

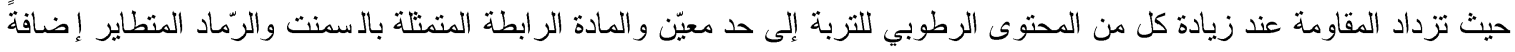

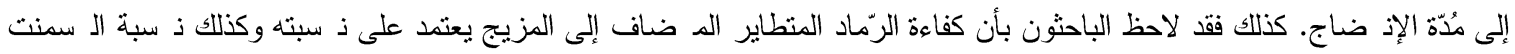

المضاف ومحتوى الرطوبة للمزيج.

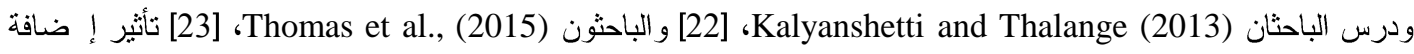
الرمّاد المنطاير على الذصائص الهندية لتربة طينية. لاحظ الباحثون بأن إضافة الرّماد المنطاير يعمل على تحسين الذصائص الدليلية

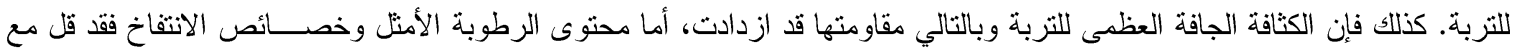
زيادة نسبة الرّماد المنطاير المضاف للتربة.

ودرس الباحثان Kumar and Preethi (2014)، [24] تأثير إضافة كل من النورة ورماد قشور الرز على خصائص الرص

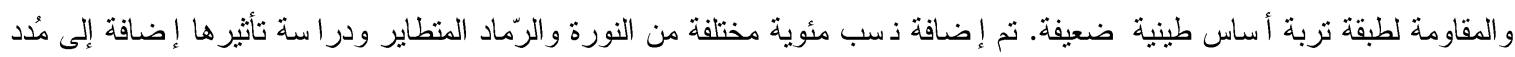

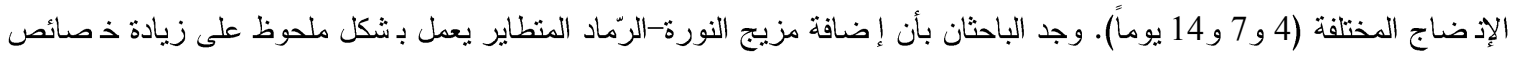

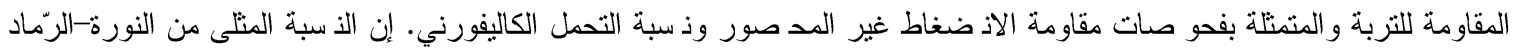

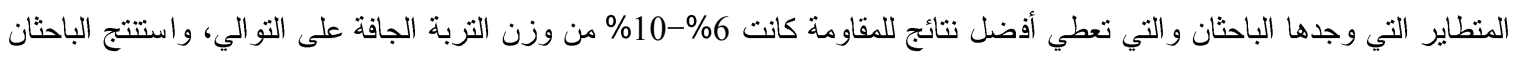

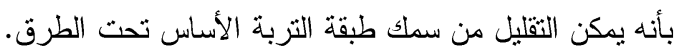

ودرس الباحث (2015) Zumrawi [6] النأثير الناتج من تثييث تربة طينية انتفاخية باستخدام كل من الرمّاد المنطاير و السمنت

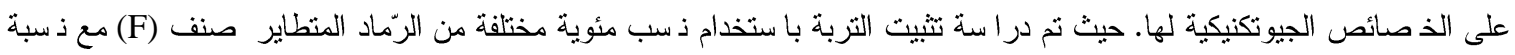

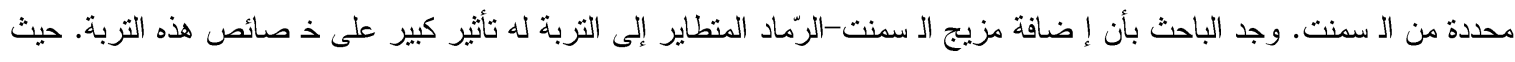

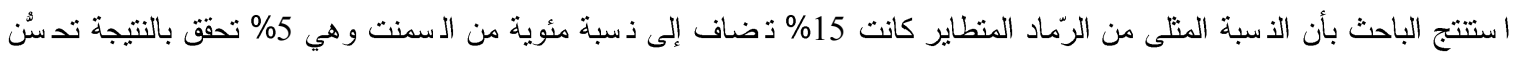

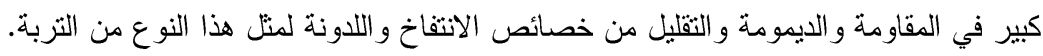

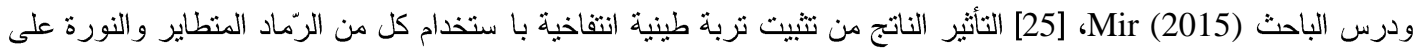

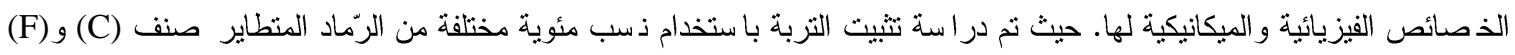

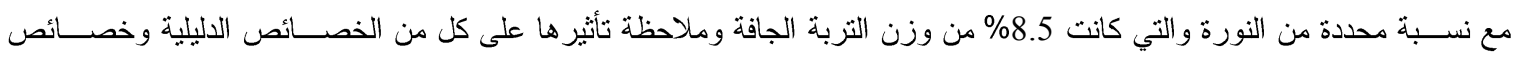

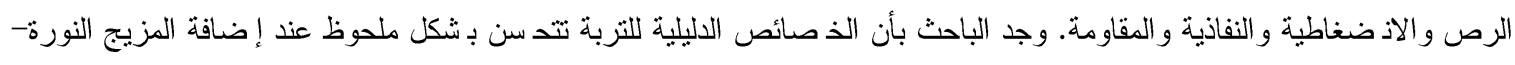

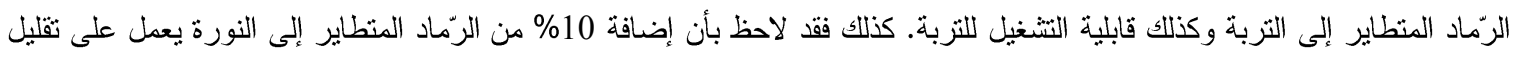

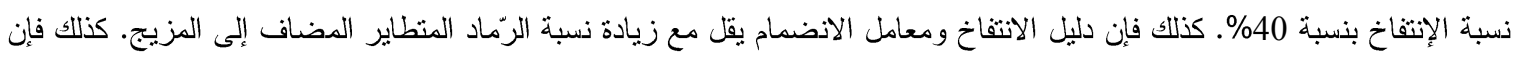

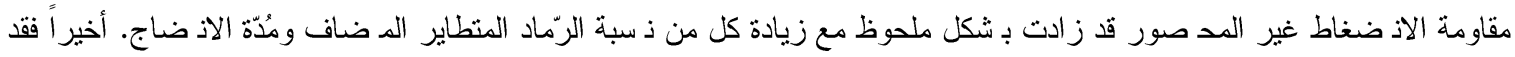

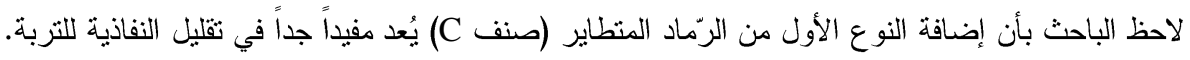




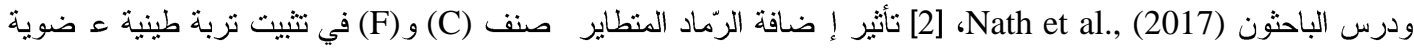

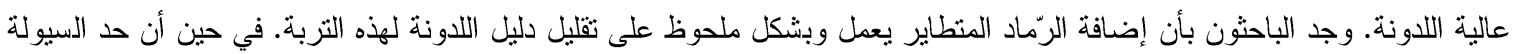

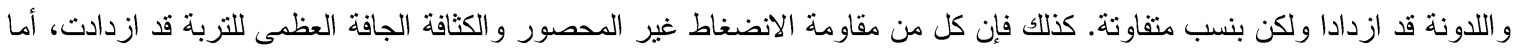

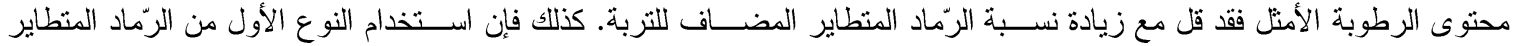

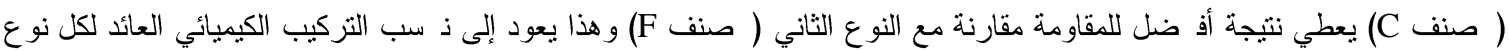
ولاسيما نسبة

4. الاستتتاجات و التوصيات للار اسات المستقبلية Conclusions and recommendations for future works تم في هذا البحث عرض مراجعة سريعة لأهم ما تو صلت إليه الدرا سات العملية الـ سابقة المنعلقة بإ ضافة بعض الد ضافات

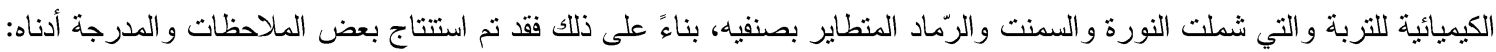
•يمكن استخدام الرمّاد المنطاير لإحداث تحسّن ملحوظ في الخصائص الدليلية والهندسية للترب الناعمة. إلا أن الرمّاد المنطاير يُحدّ مادة

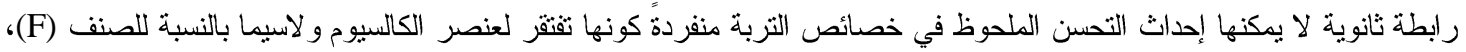

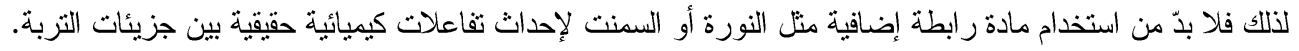

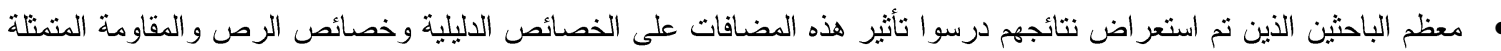

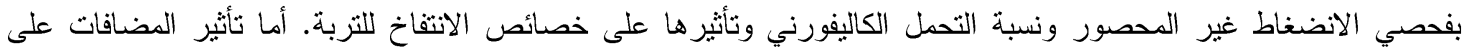
خصائص الانضمام ومعاملات مقاومة القص والصلادة و التوصيلية الهيدروليكية لم يتم التطرق لها من قبل معظم الباحثين.

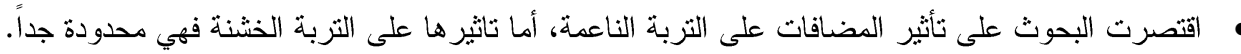

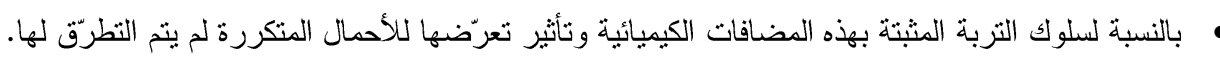
• • لا يوجد هنالك دراسات عملية حقلية، وانما اقتصرت كل الدراسات على الفحوصات المختبرية فقط. • توصي الدراسة الحالية الباحث أو مهندس الجيوتكنيك في النظر إلى الهدف الرئيسي من استخدام المضاف الكيميائي واستخدام الأنسب منها و الأكثر فاعليّة في تحسين خصائص التربة الهندسية. أدناه جدول يوضح مقارنة بسيطة بين المضافات الكيميائية الثناث، مصادر هائه وكيفية وملاعمة استخدامها مع التزب المختلفة.

\begin{tabular}{|c|c|c|c|}
\hline الزمّاد المتطاير & السّمنت & النّورة & الخاصيّة \\
\hline ناتج عرضي من عملية حرق الفحم في & مُصنّعة تجارياً & مُصنّعة تجارياً & مصدر المادة \\
\hline قليل الكلفة & مكلف & مكلف جداً & الكلفة \\
\hline التزب الناعمة وخاصةةً ذات اللدونة & كل أنواع التزبي الناعمة والخشنة النترة وكذلك & ذات الترب الناعمة وخاصةً & الملاءمة للإستخدام \\
\hline و تقليل اللدونة وزيادة قابلية التتتغيل & تحسين المقاومة والصلابة للترب & تقليل اللدونة وزيادة قابلية & الهدف من الاستخدام \\
\hline $20-5$ & $14-4$ & $10-4$ & نسب المزج (\%) من \\
\hline $\begin{array}{c}\text { تستخدم كمادة تثيت ثانوية تحتاج إلى النى النورة لإحداث التفاعلات } \\
\text { الكيميائية }\end{array}$ & تستخدم كمادة تثييت أساسية & تشتخدم كمادة تثتيت & كيفية استخدامها \\
\hline
\end{tabular}




\section{CONFLICT OF INTERESTS.}

- There are no conflicts of interest.

\section{References المصادر}

[1] Zaliha S. Z. S., Kamarudin H., Al Bakri A. M. M., Binhussain M. and Salwa M. S. S., "Review on soil stabilization techniques", Australian Journal of Basic and Applied Sciences, vol. 7, no. 5, pp. 258-265, 2013.

[2] Nath B. D., Md. Molla K. A., and Sarkar G., "Study on strength behavior of organic soil stabilized with fly ash", International Scholarly Research Notices, Article ID 5786541, pp. 1-6, 2017.

[3] Petry T. M. and Little D. N., "Review of stabilization of clays and expansive soils in pavement and lightly loaded structures history, practice and future", Journal of materials in civil engineering, vol. 14, no. 6, 2002.

[4] Pandey A. And Rabbani A., "Soil stabilization using cement", International journal of civil engineering and technology, vol. 8, no. 6, pp. 316-322, Jun. 2017.

[5] Huat B. B. K., Maail S., and Mohamed T. A., "Effect of chemical admixtures on the engineering properties ot tropical peat soils", American journal of applied sciences, vol. 2, no. 7, pp. 1113-1120, 2005.

[6] Zumrawi M. M. E., "Stabilization of pavement subgrade by using fly ash activated by cement", American journal of civil engineering and architecture, vol. 3, no. 6, pp. 218-224, 2015.

[7] Budge A. S. and Burdorf M. J, "Subgrade stabilization ME properties evaluation and implementation", Final report, Center for Transportation Research and Innovation Minnesota State University, Mankato, 2012.

[8] Little D. N., Males E. H., Prusinski J. R. and Stewart B., "Cementitious stabilization”, 79th Millennium Rep. Series, Transportation Research Board, Washington, D. C., 2000.

[9] Gaafer., Manar., Bassioni., Hesham., Mostafa., and Tareq., "Soil improvement techniques", International journal of scientific and engineering research, vol. 6, no. 12, pp. 217-222, 2015.

[10] Amiralian S., Chegenizadeh A., and Nikraz H., "A review on the lime and fly ash application in soil stabilization”, International Journal of Biological, Ecological and Environmental Sciences, vol. 1, no. 3, pp. 124-126, 2012.

[11] American Coal Ash Association, "Fly ash for Highway Engineers", fhwa.dot.gov, Jun. $27,2017$. [Online], Available: https://www.fhwa.dot.gov/pavement/recycling/fach01.cfm. [Accessed: Jan. 5, 2018].

[12] ASTM. Annual Book of ASTM Standards. Section 4, vol. 4.02, 4.08 and 4.09, West Conshohocken, 2003.

[13] Senol A., Edil T. B., Bin-Shafque M. S., Acosta H. A., and Benson C. H., "Soft subgrades stabilization by using various fly ashes", Resources, Conservation and Recycling, vol. 46, no. 4, pp. 365-376, 2006.

[14] Sas W. and Gluchowski A., "Effects of stabilization with cement on mechanical properties of cohesive soil sandy-silty clay”, Annual of Warsaw university of life sciences, vol. 45, no. 2, pp. 193-205, 2013.

[15] Nadgouda K. A. and Hegde R. A., "The effect of lime stabilization on properties of black cotton soil", Indian Geotechnical Conference, geological trends, pp. 511-514, Dec. 2010.

[16] Singh S. and Vasaikar H. B., "stabilization of black cotton soil using lime", International Journal of Science and Research, vol. 4, no. 5, pp. 2090-2094, May 2015.

[17] Sharma N. and Sahoo U. C., "Stabilization of a clayey soil with fly ash and lime: A micro level investigation”, Geotechnical and Geological Engg., DOI 10.1007/s10706-012-9532-3, Jun. 2012. 
[18] Ahmed B., Abdul Alim M., Abu Sayeed M., "Improvement of soil strength using cement and lime admixtures", Science Publishing Group, Earth Science, vol. 2, no. 6, pp. 139-144, 2013.

[19] Ochepo J. and Joseph V., "Effect of oil contamination on lime stabilized soil", Jordan Journal of Civil Engineering, vol. 8, no. 1, pp. 88-96, 2014.

[20] Shah S. J., Shroff A. V., Patel J.V., Tiwari K. C., Ramakrishnan D. R., "Stabilization of fuel oil contaminated soil - A case study", Geotechnical and Geological Engineering, vol. 21, pp. 415-427, 2003.

[21] Jongpradist P., Jomlongrach N., Youwai S., and Chucheepsakul S., "Influence of fly ash on unconfined compressive strength of cement-admixed clay at high water content", Journal Materials in Civil Eng., vol. 22, no. 1, pp. 49-58, 2012.

[22] Kalyanshetti M. G. and Thalange S. B., "Effect of fly ash on the properties of expansive soil", International Journal of Scientific and Engineering Research, vol.4, no.5, pp. 37-40, May 2013.

[23] Thomas A., Kumar K., Tandon L., and Prakash O., "Effect of fly ash on the engineering properties of soil", International Journal of Advances in Mechanical and Civil Engineering, vol.2, no.3, pp. 16-18, Jun. 2015.

[24] Kumar B. S. and Preethi T.V., "Behavior of clayey soil stabilized with rice husk ash \& lime", International Journal of Engineering Trends and Technology, vol. 11, no. 1, pp. 44-48, May 2014.

[25] Mir B. A., "Some studies on the effect of fly ash and lime on physical and mechanical properties of expansive clay", International Journal of Civil Engineering, vol. 13, no. 3, pp. 1-12, Dec. 2015. 